\title{
Un vocabulario especializado sobre la milicia: Glosario de fortificación y arte militar renacentistas"
}

\author{
MARTA SÁNCHEZ ORENSE \\ Universidad de Salamanca
}

\section{INTRODUCCIÓN}

Este artículo tiene como objetivo describir de manera pormenorizada el Glosario de fortificación y arte militar renacentistas, el cual, como su título manifiesta, recoge gran parte del vocabulario especializado de la milicia durante uno de los períodos de mayor importancia en la conformación del mismo ${ }^{1}$. Con el presente análisis esperamos poder contribuir a la difusión de este trabajo lexicográfico, cuya principal finalidad consiste en servir de ayuda en la lectura e interpretación de los numerosos tratados militares surgidos a lo largo del Renacimiento, así como de las obras consagradas a saberes científicos afines a la milicia, además de todas aquellas que por una u otra razón incorporan cualquier conocimiento de tipo castrense.

\section{EL CORPUS}

El presente glosario constituye nuestra aportación al Diccionario de la ciencia y de la técnica del Renacimiento español (DICTER $)^{2}$. Por consiguiente, la fuente documental manejada, necesaria en cualquier análisis léxico de este tipo, la conforma el corpus textual de dicho diccionario, constituido por un conjunto de 74 obras científicotécnicas, repartidas en 12 áreas de especialidad ${ }^{3}$, que comprenden el período cronológico que va desde comienzos del siglo XVI hasta el primer tercio del siglo XVII ${ }^{4}$.

\footnotetext{
* Esta investigación se integra en el marco del proyecto FFI2010-16324/FILO, financiado por el Ministerio de Ciencia e Innovación.

${ }^{1}$ «En el Renacimiento tiene lugar una auténtica "revolución militar", un cambio profundo en las armas, técnicas y tácticas, en los modos de reclutamiento, organización y financiación de los ejércitos, en las justificaciones y reglamentaciones jurídico-políticas de los conflictos bélicos, en sus implicaciones económicas, geopolíticas, sociales e intelectuales» (Campillo 2008²: 26). En Sánchez Orense (2012a: 23-39) puede verse una panorámica de esta revolución militar, junto con un análisis de los protagonistas de la misma y la enumeración de las repercusiones que trajo consigo.

${ }^{2}$ Repertorio actualmente disponible en red: <http://dicter.eusal.es/>. El Glosario de fortificación y arte militar renacentistas, además de estar accesible en esta página electrónica, puede ser consultado a través de su publicación en formato CD-ROM (véase Sánchez Orense 2012).

${ }^{3}$ Arte militar, astronomía, construcción, cosmografía y geografía, destilación, fortificación, legislación y comercio, maquinaria, matemáticas, metalurgia y minería, náutica y arquitectura naval y, por último, óptica.

${ }^{4}$ Con el fin de evitar una parcelación científica más acorde con los parámetros del siglo XXI que con los establecidos en el XVI, esta base textual fue diseñada en su momento por especialistas en la historia de las diferentes disciplinas ( $c f$. http://dicter.eusal.es). Este corpus cuenta con una versión electrónica desde el año 2005, dirigida por Mancho Duque y coordinada por Quirós García.
} 
El punto de partida es, efectivamente, este corpus, pero, como es lógico, la mayoría de los tecnicismos que conforman la macroestructura de nuestro glosario proceden de las obras catalogadas tanto como de arte militar como de fortificación:

\section{Arte militar}

- Montes, Diego (1537): Instrucción y regimiento de guerra, Zaragoza, George Coci. - García de Palacio, Diego (1583): Diálogos militares, México, Pedro Ocharte.

- Álaba y Viamont, Diego de (1590): El perfeto capitán instruido en la diciplina militar y nueva ciencia de la Artillería, Madrid, Pedro Madrigal.

- Collado de Lebrixa, Luys (1592): Plática manual de Artillería, Milán, Pablo Gotardo Poncio.

- Mendoça, Bernardino de (1596): Theórica y práctica de guerra, Anveres, Imprenta Plantiniana (1. ${ }^{a}$ ed., Madrid, Viuda de P. Madrigal, 1595).

- Mosquera de Figueroa, Christóval (1596): Comentario en breve compendio de disciplina militar, Madrid, Luis Sánchez.

- Ferrofino, Julián (mss. 1599): Descrizión y tratado muy breve y lo más probechoso de Artillería.

- Lechuga, Cristóval (1611): Discurso del Capitán Cristóval Lechuga, en que trata de la Artillería y de todo lo necessario a ella, Milán, Marco Tulio Malatesta.

- Ufano, Diego (1613): Tratado de la Artillería, Brusselas, Juan Momarte.

\section{Fortificación}

- Rojas, Christóval de (1598): Teórica y práctica de fortificación, Madrid, Luis Sánchez.

- González de Medina, Diego (1599): Examen de fortificación, Madrid, Pedro Várez de Castro.

- Roxas, Christóval de (mss. 1607): Sumario de la milicia antigua y moderna.

- Rojas, Christóval de (1613): Compendio y breve resolución de fortificación, Madrid, Juan de Herrera.

Ahora bien, dada la estrecha relación que naturalmente existe entre la arquitectura civil y la militar, debemos asimismo resaltar la trascendencia de los textos pertenecientes al ámbito de la construcción, especialmente de la siguiente pareja:

- Alberto, León Baptista (1582): Los diez libros de Architectura, Madrid, Alonso Gómez, trad. Francisco Loçano.

- Vitruvio Pollión, Marco (1582): De Architectura, Alcalá de Henares, Juan Gracián, trad. Miguel de Urrea.

\section{METODOLOGÍA Y HERRAMIENTAS INFORMÁTICAS}

Para la constitución de nuestra macroestructura procedimos, en primer lugar, a la lectura meditada de los textos renacentistas que acabamos de especificar. Tras ella se impuso, no obstante, la conclusión de que la confección de un glosario sobre el léxico militar renacentista en términos generales constituye una empresa prácticamente inabarcable, al constatar que las esferas relacionadas con la guerra son muy numerosas, lo que redunda en una cifra sumamente alta de voces con posibilidad de ser incluidas en cualquier estudio del léxico de este ámbito. Por tanto, antes de iniciar otras tareas típicas del quehacer lexicográfico, tuvimos que adoptar una serie de decisiones que aseguraran la culminación de nuestro repertorio especializado. 
De esta manera, resolvimos que lo más acertado era prescindir de los vocablos que, si bien aparecen con asiduidad en tratados militares, su mayor frecuencia de uso tiene lugar en otro tipo de textos, lo que hace suponer que, en lugar de tecnicismos militares, son términos especializados de la economía, arquitectura, construcción, matemáticas, náutica, etc. Pero, además, debido a la amplitud semántica del concepto designado a través de unidades léxicas como arte militar y milicia, nos vimos obligados a relegar de nuestro trabajo palabras o unidades pluriverbales que, a diferencia del caso anterior, no tienen cabida fuera del contexto bélico. Si tenemos en cuenta que el primer diccionario académico que recoge la unidad pluriverbal arte militar, el DRAE de 1817, la define como: «El arte de ofender y defenderse los ejércitos, atacar las plazas y defenderlas y de todo lo demás que corresponde a la guerra», es fácil suponer que cuando alguien emplea la etiqueta designativa arte de hacer la guerra y otras afines se está refiriendo no a una única disciplina o rama científica, sino al conjunto formado por varias de ellas. Así, la milicia, además de dar a conocer la historia militar de las potencias que han despuntado en el ejercicio de la guerra y analizar la organización interna, los cargos y grados militares existentes en el ejército, se encarga también del estudio de la fortificación, la poliorcética, la artillería, la táctica, la estrategia, la castrametación, la logística, etc. Pues bien, de todas estas temáticas militares susceptibles de ser contempladas, decidimos dedicarnos de manera prioritaria a la fortificación ${ }^{5}$, así como a la poliorcética ${ }^{6}$, fundamentalmente por la riqueza de sus respectivos vocabularios, si bien los términos relativos a la táctica militar ${ }^{7}$ también fueron objeto de una importante atención ${ }^{8}$. Se tuvieron en consideración asimismo, aunque ya en un segundo plano, los términos pertenecientes a las ramas militares de la estrategia ${ }^{9}$, la logística ${ }^{10}$ y la castrametación ${ }^{11}$.

En cambio, descartamos hacernos eco del campo de la artillería ${ }^{12}$ fundamentalmente porque un estudio sobre el léxico artillero hubiera producido un glosario de la misma extensión o incluso mayor que el presente, lo que ha quedado demostrado con el confeccionado por Cristina Blas Nistal ${ }^{13}$.

Tras el establecimiento de estos campos científicos pudimos centrarnos en la recopilación de la terminología militar objeto de estudio, tarea que se vio facilitada por un

\footnotetext{
${ }^{5}$ «Ciencia que enseña a disponer todas las fábricas y obras que son necesarias para conseguir el fin de la guerra» (Fernández Mancheño 1822).

${ }^{6}$ «Arte de atacar y defender las plazas fuertes» (DRAE 2001). Para más datos sobre esta voz, la cual, curiosamente, no cuenta con ocurrencias en los textos militares renacentistas, vid. Sánchez Orense (2012b: 469).

7 «Mil. Arte de disponer, mover y emplear la fuerza bélica para el combate» (DRAE 2001).

${ }^{8}$ «La fortificación y la táctica se enlazan sin confundirse; se engranan sin entorpecerse; se completan mutuamente; marchan, crecen, juegan con el mismo fin, en el mismo teatro, con reglas casi idénticas por lo análogas» (Almirante 1869: s. v. fortificación).

9 «Arte de dirigir las operaciones militares» (DRAE 2001).

10 «Parte de la organización militar que atiende al movimiento y mantenimiento de las tropas en campaña» (DRAE 2001).

${ }^{11}$ «Arte de ordenar los campamentos militares» (DRAE 2001).

12 «Arte de construir, conservar y usar todas las armas, máquinas y municiones de guerra» (DRAE 2001).

${ }^{13}$ Este se incluye en su Tesis doctoral Estudio léxico de los tratados de artillería españoles del siglo XVI, realizada en el marco del proyecto del DICTER.
} 
programa de búsquedas complejas, denominado UltraEdit, que posee la ventaja de localizar las voces en las concordancias del corpus. Como es sabido, el empleo de los recursos informáticos en las investigaciones lexicográficas resulta imprescindible ( $c f$. Arntz y Picht 1995: 219).

Posteriormente, procedimos a la lematización de este caudal léxico en una base de datos informatizada, el fichero de vaciado, que constituye la ficha lexicográfica propiamente dicha. Debemos especificar que desde el comienzo del proyecto del DICTER hasta el momento actual esta base de datos, diseñada con FileMaker, ha experimentado constantes mejoras. A día de hoy, comprende distintos campos que se agrupan bajo los nueve bloques temáticos siguientes:

1. Datos relativos a la lematización.

2. Información histórica, etimológica y morfológica.

3. Clasificación semántica.

4. Definición e información lexicográfica.

5. Ejemplos.

6. Información enciclopédica.

7. Observaciones semánticas.

8. Otras observaciones.

9. Imagen e información sobre la misma.

Estos bloques temáticos enumerados se encuentran organizados en cuatro pestañas, lo que permite una mejor visualización de la información que se va incorporando: forma e historia, clasificación semántica, ejemplos e información y, por último, imagen, que en nuestro caso resultó ser de una gran utilidad dados los múltiples conceptos especializados a los que fue preciso adjuntarles una determinada ilustración para una mejor comprensión.

Este sistema de pestañas informáticas, del que ofrecemos una muestra, ha sido posible gracias al empleo de versiones de FileMaker posteriores a la séptima. 

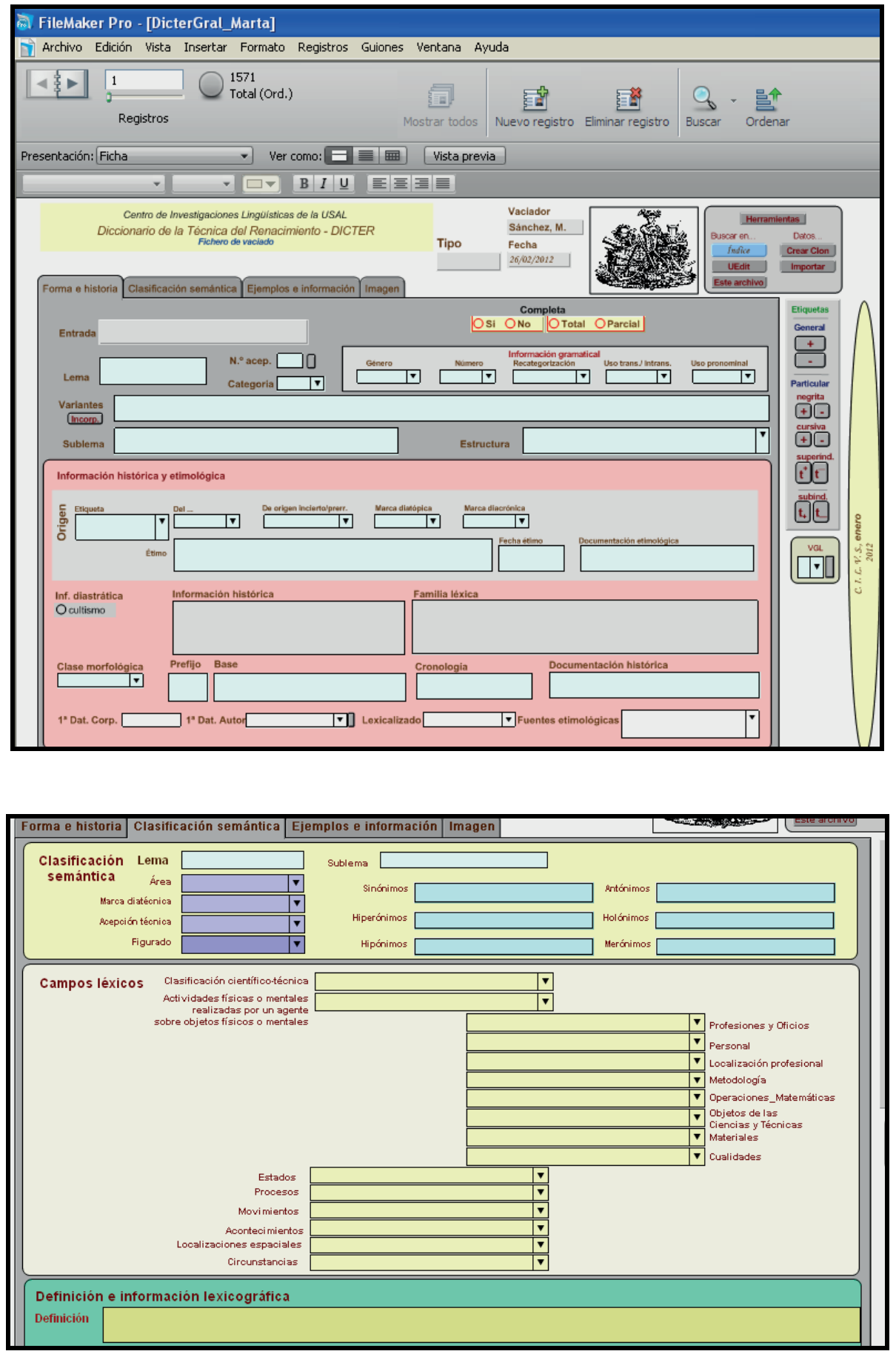

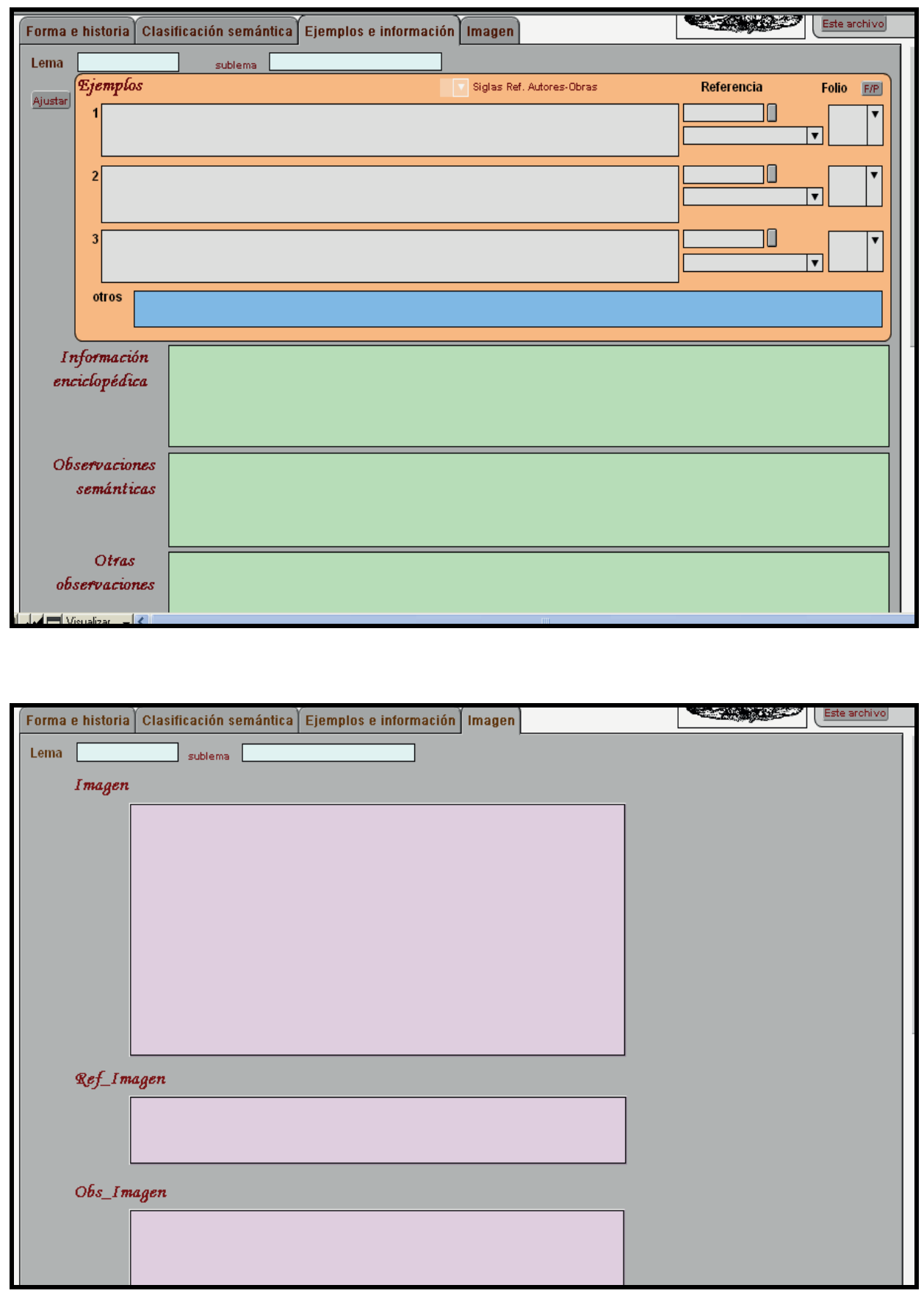

Figuras 1-4: Ficha lexicográfica 


\section{ESTRUCTURA}

Como otros repertorios, el Glosario de fortificación y arte militar renacentistas «se halla construido y organizado en torno a dos ejes fundamentales: una macroestructura, constituida por todas sus entradas dispuestas de acuerdo con un determinado criterio ordenador, junto a una microestructura o conjunto de informaciones - también dispuestas de acuerdo con un determinado patrón o patrones - que se ofrecen dentro del artículo lexicográfico» (Porto Dapena 2002: 135).

\subsection{La macroestructura y algunas cuestiones relativas a la lematización}

Como acabamos de declarar, por nomenclatura o macroestructura se entiende la suma de lemas o entradas que se registran en una obra lexicográfica. Así, la de nuestro glosario está formada por un total de 1149 entradas, que se reparten del siguiente modo: 593 lemas encabezan el artículo lexicográfico, 133 son remisiones de unidades pluriverbales (estructuras sintagmáticas y locuciones) y 423 son remisiones de variantes ortográficas.

Como es habitual en la práctica lexicográfica, estas 1149 entradas han sido dispuestas en orden alfabético.

En la lematización de las voces el criterio seguido fue la norma ortográfica del castellano actual, por lo que la consulta de las últimas obras lexicográficas y ortográficas de la Real Academia Española resultó fundamental. En este sentido, son entradas de nuestro glosario aproche, asaltante, belicosamente, convoy, cuartel, espolonada, facienda, forrajear, gasón y vaivén, por citar solo algunos ejemplos, a pesar de que ninguna de estas formas se documenta en el corpus analizado, sino solo sus variantes aproge, aproje, aproxe, assaltante, bellicosamente, comboy, quartel, spolonada, fazienda, hazienda, forregear, gazón, baibén, baybén, bayvén y vaybén.

A propósito de la lematización de las voces, en los casos de fianco y terrapleno se ha decidido presentarlos como lemas independientes de flanco y terraplén, de acuerdo a su diferente origen, aunque estas dos últimas formas sean las empleadas en la actualidad. Es decir, fianco y terrapleno son voces que proceden del italiano, frente a flanco y terraplén, que lo hacen de la lengua gala, lo que invalida la consideración como meras variantes de las unas con las otras ${ }^{14}$.

La diferente procedencia que, según creemos, poseen acometido ${ }^{15}$ y acometida ${ }^{16}$ hizo decantarnos, igualmente, por su lematización independiente, al igual que ocurre en ofensivo $^{17}$ y ofensiva ${ }^{18}$.

\footnotetext{
${ }^{14}$ Por lo que respecta al $D R A E$ 2001, solo se contempla esta doble lematización en el caso de terraplén-terrapleno, aunque, como sus correspondientes paréntesis etimológicos revelan, no porque los académicos consideren que terrapleno es un italianismo, frente al galicismo terraplén, sino por tratarse a su juicio de un derivado de terraplenar.

${ }^{15}$ De acometer, con sufijo -do.

${ }^{16}$ De acometer, con sufijo -(i)da.

${ }^{17}$ De OFFENSUM, participio latino de OFFENDERE (cast. ofender), con sufijo -ivo.

${ }^{18}$ De ofensivo. «Es importante en la historia de -ivo el proceso de sustantivación, producto de la elipsis en frases nominales del antecedente sustantivo de un adjetivo en -ivo» (Pharies 2002: s. v. -ivo).
} 
Por otro lado, la tratadística militar renacentista da cuenta de una gran variedad de formas para referirse a la «parte de una fuerza armada que en una marcha, ataque, etc., va delante» (DUE: s. v. vanguardia): abanguarda, abanguardia, avanguardia, banguardia, vanguarda y vanguardia. A pesar de haber considerado en nuestro glosario que el término catalán $A V A N T G U A R D A$ es el principal responsable de todos estos significantes, como en la existencia de muchos de ellos ha podido influir de manera decisiva la voz italiana VANGUARDIA, según admite el DCECH (s. v. guardar), finalmente nos decidimos por establecer cuatro entradas distintas para este concepto: avanguarda, cuya variante es abanguarda; avanguardia, y abanguardia y avanguardia como sus variantes; vanguarda, que solo se documenta en esta forma; y, por último, vanguardia, lema susceptible de aparecer en el corpus con variación ortográfica $(b \circ v)$.

El hecho de que los autores más imbuidos en la cultura y en la lengua de Italia, como es el caso de Luis Collado, hagan uso de vanguardia, en detrimento del resto de unidades léxicas, nos persuadió de que tomábamos la decisión correcta. Además, de acuerdo con los etimologistas, las voces simples guarda ${ }^{19}$ y guardia ${ }^{20}$ derivan de étimos distintos, circunstancia que, en el caso de estar presente en la conciencia lingüística de los hablantes, puede condicionar su selección léxica, lo que creemos que corrobora nuestra determinación.

Por las mismas razones, tanto retaguarda como retaguardia adquieren en este glosario el rango de lemas de cabecera o entradas:

retaguarda, retaguarda [del cat. reraguarda (formado con rera 'tras', del lat. retro). Covarr.; Oudin y Aut. (DCECH). García de Palacio, Diálogos militares, 1583]. sust. Mil. Parte de una fuerza armada que en una marcha, ataque, etc., va detrás.

García de Palacio, Diálogos militares, 1583, fol. 146r: En cayendo, pues, alguno de los de la primera hilera, entrava luego el que estava detrás d'él, en la segunda, y el de la tercera, en la segunda; el de la quarta, en la tercera. Y, assí, con mucha presteza se rehazían todas las órdenes, consumiéndose y cevando solamente de la retaguarda, que todas las otras siempre avían de estar enteras y pelear ordinaria y ordenadamente, de manera que antes eran consumidas, que rotas ni desbaratadas.

retaguardia, rectaguardia, retaguardia [del cat. reraguarda (formado con re$r a$ 'tras', del lat. retro), modificado luego bajo el influjo del it. retroguardia. 1590, Juan de Castellanos, Hist. N. Granada; Oudin y Aut. (DCECH). Montes, Instrucción y regimiento, 1537]. sust. Mil. Parte de una fuerza armada que en una marcha, ataque, etc., va detrás.

Montes, Instrucción y regimiento, 1537, fol. Xr: Quando el exército començare a marchar la buelta adonde están los enemigos, han de echar de banguardia la gente más plática en la guerra y, tras aquélla, vaya el cuerpo de la batalla, y luego la artillería, y de retaguardia vaya la gente que no es tan plática [...]. Mas si conosciere que los enemigos estuvieren más pujantes que no ellos y se quisieren retirar, echen la gente más plática de retaguardia y la que no es tan plática vaya de banguardia con la artillería.

${ }^{19}$ «Del germ. WARDA» (DCECH: s. v. guardar).

${ }^{20}$ «Del gót. WARDJA 'el que monta guardia', 'centinela, vigía', influido en su significado por el lat. custodia 'acción de guardar', 'retén de soldados'» (DCECH: s. v. guardar). 
Asimismo, somos conscientes de que nuestro modo de proceder en la lematización de los verbos pronominales requiere también de explicaciones adicionales. Para este importante aspecto, partimos de la declaración de intereses de los autores del DRAE, especificada en las «Advertencias» a la vigésima segunda edición: «Los verbos aparecen en infinitivo. Si solo tienen conjugación pronominal se representan de este modo». De esta forma, cuando uno de nuestros tecnicismos verbales ostenta varias acepciones, aunque alguna sea pronominal, si al menos uno de sus sentidos relevantes es ajeno a ese régimen verbal, de acuerdo con el $D R A E$, el lema del verbo en cuestión no termina en -se:

atrincherar, atrinchear, atrincherar [de trinchera $(D C E C H)$. Rojas, Teórica fortificación, 1598]. v. tr. Fort. Defender algo con trincheras o construir trincheras en un sitio $(D U E)$.

2 [Collado, Plática Artillería, 1592]. v. prnl. Fort. Ponerse una persona en una trinchera para defenderse $(D S A L)$.

Ahora bien, al ser el $D R A E$ un diccionario general, está claro que sus lemas en -se, como acaserarse, el que les sirve a los académicos para ejemplificar esta situación, o arrepentirse, entre otros, responden al hecho constatado de que en ellos la conjugación pronominal es la única posible. En cambio, nuestras entradas acamparse, aliarse, coligarse, confederarse, encastillarse, enseñorearse y ligarse, al formar parte de un repertorio de especialidad centrado en la época renacentista, no conllevan necesariamente que el pronominal sea el único régimen verbal posible. De hecho, excepto en el caso de coligarse, del que los académicos solo admiten esta posibilidad, el resto de los verbos enumerados cuentan también con usos transitivos e intransitivos. Queremos advertir, en definitiva, que el modo en el que fueron lematizados estos términos simplemente certifica que sus significados atendidos solo se detectaron en construcciones pronominales, con independencia de que en otro tipo de acepciones su régimen verbal pueda o no ser este.

Por último, con respecto a la presencia en la macroestructura de voces homonímicas cabe destacar que el criterio etimológico y diacrónico es el que ha predominado en su tratamiento lexicográfico. Según este criterio, se produce homonimia si dos étimos distintos han llegado en su desarrollo a una confluencia en su forma fónica. Por tanto, estas unidades poseen una representación autónoma en nuestro glosario, es decir, procedimos a asignar a cada unidad homónima su propia entrada, tal como se constata en este ejemplo:

real', real [del lat. regalis. Real 'perteneciente al rey'. Doc. de 1188; Berceo (DCECH). Collado, Plática Artillería, 1592]. adj. Fort. Dicho de una construcción defensiva: permanente, sólida y mayor que otras de su misma clase.

real $^{2}$, real [del ár. rahl (vulgar rahál) que significa 'lugar donde se hace alto en un camino', 'campamento', 'majada, redil', 'rebaño'. Real 'predio rústico', 'campamento', 'cabaña'. Reyal, Cid; real, doc. murciano de 1275 (DCECH). Fernández de Enciso, Suma de Geographía, 1530]. sust. u. t. en pl. con el mismo significado que en sing. Mil. Campamento o conjunto de instalaciones donde se establece temporalmente un ejército en campaña. 


\subsection{La microestructura}

La microestructura es la ordenación de los elementos que conforman el artículo lexicográfico y está formada por la entrada o lema y por las informaciones proporcionadas acerca de esa unidad léxica. En nuestro caso, son múltiples las informaciones que proporcionamos sobre cada uno de los lemas establecidos, las cuales derivan de los nueve bloques temáticos anteriormente detallados a propósito de la descripción de la ficha lexicográfica empleada. Uno de los artículos lexicográficos más completo de este glosario terminológico es el de cortina $^{21}$ :

cortina, cortina [del lat. tardío cortina 'íd.', derivado del lat. vg. cors, -tis, lat. cohors 'recinto'. Cortina 'paño con que se cubren puertas, ventanas, camas, etc.'. Berceo, Mil. (DCECH). Álaba, Perfeto capitán, 1590]. sust. Fort. La porción de muralla comprendida entre dos baluartes. $\quad$ S (fig. 48)

Álaba, Perfeto capitán, 1590, fol. 88v: Y desde que se començare a batir siempre se vaya continuando con gran priessa de día y de noche, cruzando la batería, dándola a los lados de los baluartes, por estorvar el daño que las pieças de las casamatas hazen, echándolas por tierra, con que quedará el lugar más acomodado de subir la fortaleza, batiendo también la cortina que está en medio de los dichos baluartes.

SIN.: cortina franca, cortina limpia, cortina parcial.

FAM.: descortinar.

ENCICL.: Díaz Capmany (2004: 30): «La cortina era el tramo de terraplén comprendido entre dos baluartes; por estar entre dos flancos era la parte más defendida. La longitud de las cortinas estuvo siempre íntimamente relacionada con el alcance de las armas empleadas en su defensa, es decir, las que tenían que flanquearlas».

2 [Roxas, Sumario milicia, 1607]. sust. Constr. Trozo continuo de pared o muralla (DSAL: s. v. lienzo).

Roxas, Sumario milicia, 1607, fol. 77r: Largo de la frente o cortina del baluarte, 250 pies. // Lechuga, Discurso de la Artillería, 1611, pág. 241: El fosso a de ser ancho, por la parte de las cortinas de los baluartes, quando menos, 120 pies, y por las otras partes, lo que precisamente pide, para que los baluartes puedan guardar el fosso.

SIN.: lienzo.

ENCICL.: Lorenzo Celorrio (1996): Lienzo. Porción de muralla comprendida entre dos elementos cualesquiera que rompan la uniformidad del muro tales como torres, cubos, esquinas o precipicios.

$\sim$ franca [Rojas, Teórica fortificación, 1598]. cmpt. sintag. Fort. La porción de muralla comprendida entre dos baluartes.

Rojas, Teórica fortificación, 1598, fol. 41r: Para hazer el repartimento en esta plaça en triángulo, se dividirá, como dicho es, en cinco partes la frente del recinto, que en este caso es la $\mathrm{AB}$ y tiene de frente 600 pies, que, divididos en cinco partes, caben a cada una a 120. Y éstos se rebatirán de ambos estremos de la frente del recinto para sacar los traveses, como lo muestran $\mathrm{AC}$ y $\mathrm{CB}$ en la passada figura, dexando la cortina franca, del un través al otro, de 360 .

SIN.: cortina ${ }_{1}$, cortina limpia, cortina parcial.

${ }^{21}$ Por motivos de espacio, renunciamos a ofrecer este artículo lexicográfico de manera íntegra. 


\subsubsection{Variantes gráficas}

Al centrarnos en un período histórico esencial en la evolución del español, debido a su gran riqueza gráfica, creímos fundamental recoger en la microestructura todas las posibles formas con las que aparecen los lemas en el corpus. Por consiguiente, después de la entrada se especifican sus variantes.

Asimismo, esta información aparece en la macroestructura del glosario en forma de reenvíos o remisiones de las variantes gráficas a la forma canónica lematizada, además de contar con un índice final que recoge todas estas formas.

Con respecto a este destacado asunto, queremos realizar algunas precisiones. En primer lugar, consideramos que çitadela es una variante del lema ciudadela, significante que acaba imponiéndose como adaptación castellana del término italiano CITTADE$L L A$, porque, si bien es bastante probable que en esta fijación haya desempeñado un papel fundamental la voz patrimonial ciudad, no es menos cierto que tanto ciudadela como çitadela poseen el mismo origen, esto es, el italiano CITTADELLA.

Tanto en este como en el caso del galicismo botasilla ${ }^{22}$ - presente en nuestro corpus solo en la forma botasela - estaríamos en las primeras fases del proceso de integración formal que todo préstamo experimenta en la lengua receptora, de acuerdo con la clasificación de Otaola Olano (2004: 78-79), a saber, las de préstamo sin alteración o solo adaptado bien fónica o bien morfológicamente, frente a la situación final de préstamo plenamente integrado. Exactamente lo mismo ocurre con el galicismo interpre$s a^{23}$, puesto que, como atestigua la confluencia en los textos manejados de las unidades léxicas antepresa, entrepresa e ynterpresa, aún no contaba en el siglo XVI con una forma fija en castellano.

Por otro lado, en referencia al período cronológico estudiado, se ha señalado ya «una fluctuación de tendencias en la lexicalización de ciertos vocablos compuestos, como sucede con carromato / carros matos; aguardiente / agua ardiente, etc., lo que pone de manifiesto la falta de fijación terminológica en esta época» (Mancho Duque 2003: 34). Como demuestra la tratadística manejada, este fenómeno también puede producirse en términos que, si bien no son compuestos en última instancia, están relacionados grosso modo con este procedimiento morfológico: por ejemplo, casamata, término que en nuestra lengua es un italianismo, del it. CASAMATTA, formado a su vez por la combinación de casa y matta ( $c f$. DCECH: s. v. casa); y contrabatería, que pese a contar con una ascendencia gala, seguramente llegó a interpretarse como el resultado de la unión de contra más batería. En conclusión, la presencia en el corpus de ocurrencias como las siguientes, nos ha llevado a establecer las formas casa mata y contra batería como variantes de los lemas casamata y contrabatería:

El muro ha de ser bien fraguado; ha de tener sus traveses que jueguen por lo baxo del fosso, con que haya de través a través ciento y cinqüenta passos o, a lo menos,

\footnotetext{
${ }^{22}$ «Del fr. BOUTE-SELLE (s. XVI). La forma más antigua fue botasela (1595-1794), que más tarde fue castellanizada en botasilla (1705, Gili)» (DCECH: s. v. botar).

${ }^{23}$ «Del fr. ENTREPRISE» (DCECH: s. v. prender).
} 
casas matas, para que la artillería pueda jugar dentro d'ellas por lo alto y por lo baxo (Montes 1537: XVIIr).

No quiero aprovar por esso que, pieça contra pieça, no serán mejores los cañones que los medios, empero, por quanto el deffender una plaça y hazer la contra dicha batería a la de afuera, tomaría de mejor gana los medios cañones (Ufano 1613: 170).

Por último, con respecto a la entrada bastión ${ }^{24}$, además de la forma coincidente con ella, también establecemos como variante suya bestión, sobre todo porque así parecen juzgarla Corominas y Pascual: «La variante bestión, frecuente en el s. XVI, se debe a influencia de vestir» (DCECH: s. v. bastión). De todas formas, debemos advertir que el $D R A E$ (2001), a diferencia de nuestro modo de proceder, sí reserva una entrada para bestión, donde remite a bastión. Probablemente esta lematización esté directamente relacionada con el hecho de recoger otro bestión, derivado de bestia, es decir, un término homónimo del bestión dependiente de bastión. En definitiva, al obrar de este modo, los académicos consiguen marcar distancia entre estas dos formas léxicas homónimas, lo que evidentemente no precisamos hacer nosotros ${ }^{25}$.

\subsubsection{Información histórica, etimológica y morfológica}

En cualquier glosario de tipo histórico resulta imprescindible la información relativa a la etimología y a la datación de cada una de las voces, motivo por el que tuvimos en cuenta estos aspectos. Así, nos servimos, preferentemente, del Diccionario crítico etimológico castellano e hispánico $(D C E C H)$. Solo para aquellos términos no recogidos en este repertorio, o cuyo origen no estaba claro con los escasos datos ofrecidos, recurrimos a la consulta de, entre otros, Le Grand Gaffiot: dictionnaire latin-français, el Nuevo diccionario etimológico latín-español y de las voces derivadas de Santiago Segura Munguía y su más reciente Diccionario por raíces del latín y de las voces derivadas, el Nuevo diccionario latino-español etimológico de Raimundo de Miguel, así como el Trésor de la langue française $(=T L F)$, el Tesoro della lingua italiana delle origini $(=T L I O)$, el Grande dizionario della lingua italiana de Salvatore Battaglia y el Dizionario etimologico italiano de Battisti y Alessio. Nos valimos, asimismo, de los trabajos de destacados etimologistas, como es el caso de Colón Doménech (2008), cuyas investigaciones acerca del origen del término revellín, por ejemplo, resultaron ser fundamentales. Por último, en conqueridor, contraminar, contramuro, espolón, explanada y pina consideramos acertado anotar el origen postulado por el DRAE (2001), debido a que, si bien no

24 «Del it. BASTIONE 'íd.', derivado de BASTİA 'obra fortificada', forma de origen dialectal genovés, piamontés o lombardo, en lugar de BASTITA derivado de BASTIRE 'construir'» (DCECH).

${ }^{25}$ En cambio, en el caso de arce y arcén nos hemos decantado por la solución adoptada por el $D R A E$. Por consiguiente, para estas dos unidades léxicas nuestro glosario consta de dos lemas, arce y arcén, cada uno de los cuales posee distintas variantes: arce, arçe, arço y arze, por lo que respecta al primero; y arcén y arzén en el caso del segundo. La razón reside en que, a pesar de considerar como responsable directo de estas dos formas al latín arcaico y vulgar $A R G E R, A R G \breve{E} R I S$, de ahí que en nuestro glosario el étimo propuesto en ambas sea este, como, según indica la mayoría de las obras lexicográficas consultadas, las primeras documentaciones de arce son anteriores a las de arcén, no podemos descartar que, en realidad, esta última derive de la primera. En resumen, en este caso hemos optado por la doble lematización por considerar que, dado su carácter tan especial, esta era la decisión más acertada. 
se trata de un diccionario etimológico, es el que de manera más clara, de todos los consultados, se pronuncia al respecto del origen de estas voces.

Debemos matizar que no solo ofrecemos información sobre los vocablos cuya presencia en español se explica por los frecuentes préstamos de unas lenguas a otras, sino que, efectivamente, nos preocupamos también por indicar si se está ante un término derivado o ante uno compuesto, al igual que especificamos la base de derivación y las unidades simples que integran el compuesto.

De hecho, si es posible, tras aportar todos los datos pertinentes respecto al lema de cabecera, con la excepción de la información enciclopédica, si la hay, señalamos la familia de palabras (FAM.), que da cuenta de la serie completa de voces emparentadas morfológicamente con la entrada:

acometer, acometer, hacometer [de cometer y éste del lat. commîttěre. Cid, etc., pero menos frecuente que cometer hasta el s. XIV (DCECH). Fernández de Enciso, Suma de Geographía, 1530]. v. tr. u. t. c. intr. Mil. Lanzarse contra alguien para causarle daño o para vencerle.

Montes, Instrucción y regimiento, 1537, fol. Xv: Y por los lados, y en las postreras hileras del esquadrón, van también otras hileras de cosseletes; y la arcabuzería va delante, y en torno del esquadrón. Y esto se haze quando son los enemigos muchos, porque el esquadrón vaya más fortificado, y no puede ser roto por ninguna parte que le acometan.

SIN.: atacar, combatir 3 , embestir 2 , ofender.

ANT.: defender 2 .

FAM.: acometedor, acometida, acometido, acometimiento.

ENCICL.: Terr.: En la Milicia, V. atacar. // DUE: Atacar físicamente a alguien, o atacar un sitio donde hay alguien: 'Acometieron nuestras posiciones de madrugada'.

Ahora bien, aunque en principio mantuvimos al margen de este apartado los préstamos, en los casos en los que se documenta tanto el vocablo patrimonial como el cultismo correspondiente, atendiendo a su evidente vinculación, consignamos cada uno de ellos en la familia del otro:

fosa, fosa, fossa [tomado del lat. fössa 'excavación', 'fosa', 'tumba', 'canal', propiamente participio femenino de fŏdĕre 'cavar'. 1542, Diego Gracián $(D C E C H)$. Montes, Instrucción y regimiento, 1537]. sust. Fort. Zanja profunda que circunda toda la plaza, fortaleza, etc. (Terr.: s. v. foso).

FAM.: contrafosa, fuesa.

fuesa, fuessa [del lat. fŏssa 'excavación', 'fosa', 'tumba', 'canal', propiamente participio femenino de fŏděre 'cavar'. Fuesa tiene, por lo común, la ac. de 'tumba. Doc. de 1200, Burgos; Berceo (DCECH). Montes, Instrucción y regimiento, 1537]. sust. Fort. Zanja profunda que circunda toda la plaza, fortaleza, etc. (Terr.: s. v. foso).

FAM.: contrafosa, fosa. 
Finalmente, cuando existe, añadimos la información histórica que propone el $D C E C H$. Junto a esta, nuestra aportación consiste en facilitar la primera documentación del corpus textual manejado, y tanto del lema de cabecera como de cada acepción, además de las distintas unidades pluriverbales.

\subsubsection{Categoría e información gramatical}

Damos cuenta igualmente de la clase de palabras, aspecto del que las únicas posibilidades son sustantivo, adjetivo, verbo y adverbio, lo que resulta esperable si tenemos en cuenta que son estas las categorías predominantes en los lenguajes especializados. Además, por lo que respecta a las unidades pluriverbales, comunicamos mediante las siguientes abreviaturas el tipo de que se trata en cada caso: loc. adj. (locución adjetiva), loc. v. (locución verbal), loc. adv. (locución adverbial) y, por último, cmpt. sintag. (compuesto sintagmático).

Por otro lado, solo consignamos el género gramatical cuando este es relevante, como ocurre cuando, en lo que respecta a esta importante cuestión, el uso de un determinado término, de acuerdo con el corpus manejado, difiere del que posee en la actualidad. Así pues, la razón de que en nuestro glosario en el lema centinela, por citar solo un ejemplo, se especifique que su género es el femenino se debe a la constatación de que en la tratadística renacentista los determinantes que acompañan a esta voz adoptan siempre la forma femenina, frente al género masculino que coinciden en señalarle todos los diccionarios contemporáneos.

Por consiguiente, no se encuentra entre nuestros objetivos la indicación del género gramatical de cada una de las unidades léxicas recogidas, sino que, en relación con este aspecto, consideramos que lo único útil e interesante era advertir de las anomalías detectadas, de lo que, efectivamente, nos ocupamos. Por ello, tras localizar varias ocurrencias que mostraban un empleo masculino del sustantivo blinda, a pesar de que ciertamente, y en consonancia con el DRAE (2001) por ejemplo, lo más habitual era el género femenino, optamos por adjuntarle a f. (femenino) u. t. c. m. (usado también como masculino). Paralelamente, nuestro glosario dispone de la abreviatura u. t. c. f., presente en alarde, camarada y puente, entre otras voces.

En el caso del número nos valimos del acertado sistema establecido por la corporación académica: pl., es decir, «plural» (como en aproche ${ }_{2}$, fuerza $a_{2}$, pertrechos y víveres); u. m. en pl. con el mismo significado que en sing., que es la abreviatura de «usado más en plural con el mismo significado que en singular» (por ejemplo, en bastimento, despojo $_{2}$, munición y vitualla); u. t. en pl. con el mismo significado que en sing, que lo es de «usado también en plural con el mismo significado que en singular» (en presa y $_{3}$ en real $_{1}^{2}$ ); y u. m. en pl. «usado más en plural» (abrojo, cuartel, diente ${ }_{1}$, través ${ }_{2}$, etc.).

En varias ocasiones fue preciso ofrecer otros tipos de información gramatical diferentes de los hasta ahora tratados. Por ejemplo, debido a la asiduidad con la que se sustantivan las locuciones adjetivas de (a) caballo y de (a) pie, resultó necesario el empleo en ellas de la abreviatura u. t. c. sust., que marca «usado también como sustantivo». Incluimos, del mismo modo, las abreviaturas del $D R A E$ «prnl.» y «u. t. c. prnl.» sobre el uso pronominal de algunos verbos. Ahora bien, la información gramatical más 
relevante en relación a las numerosas formas verbales recogidas es la relativa a su régimen transitivo o intransitivo, aspecto del que dependen estas abreviaturas: tr. (transitivo), intr. (intransitivo) y u. t. c. intr. (usado también como intransitivo).

\subsubsection{La marcación}

En palabras de Fajardo Aguirre (1996-1997: 31), «la marcación es el recurso o procedimiento que se utiliza en el diccionario para señalar la particularidad de uso, de carácter no regular, que distingue a determinados elementos léxicos».

De acuerdo con la ordenación de Porto Dapena (2002), las marcas se clasifican en cuatro grupos: diacrónicas, diatópicas, diafásicas y, por último, las diastráticas, «entre las que por cierto podemos incluir las técnicas y de especialidad» (Porto Dapena 2002: 257-258). Para Garriga Escribano (2003), en cambio, estas últimas deben incluirse en un apartado específico, mientras que son las diafásicas y las diastráticas las que para él forman un grupo único.

En cualquier caso, resulta evidente que en un repertorio lexicográfico de especialidad, como el que presentamos, la distinción de la ciencia o de la técnica a la que pertenece cada una de sus palabras o acepciones se convierte en una tarea de vital importancia. En consonancia con la práctica lexicográfica actual, hicimos uso de un completo sistema de abreviaturas.

En primer lugar, marcamos con Mil. (milicia) todas aquellas realidades militares que o bien no pertenecen o no son exclusivas de la fortificación, de la poliorcética o de la artillería, puesto que, dada su gran trascendencia, estas tres ramas del arte militar cuentan con una marca propia: Fort. (fortificación), en el caso de las dos primeras, y Art. para la artillería.

A pesar de que en la confección de nuestro glosario también nos valimos de las correspondientes marcas de geometría y construcción, a saber Geom. y Constr., como evidencia el siguiente gráfico, son escasas las acepciones que disponen de una de ellas:

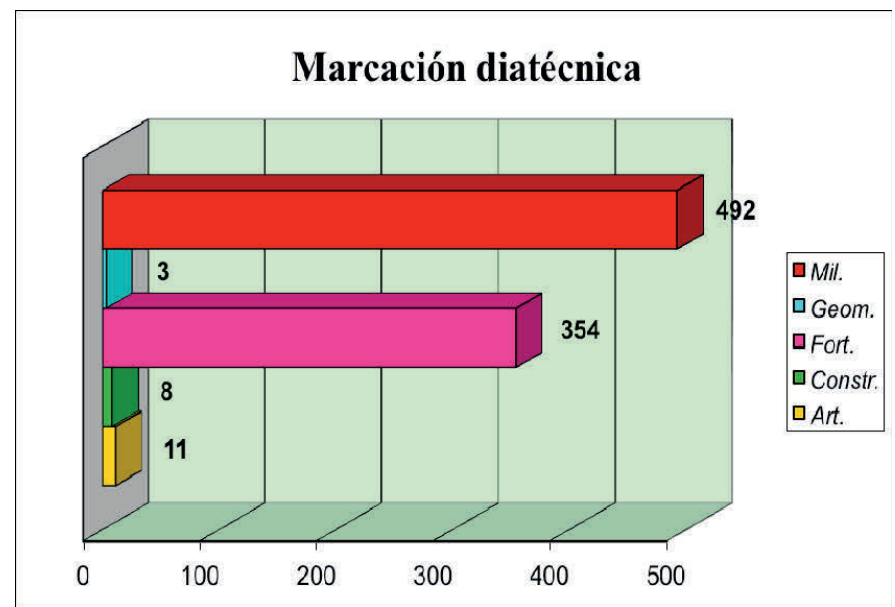

Figura 5: Gráfico con las marcas temáticas utilizadas 
Debemos precisar, por otro lado, que «las marcas no son excluyentes, de tal manera que donde aparezca una no hay ninguna razón para que no aparezca otra» (Jiménez Ríos 2001: 245). Por consiguiente, no debe resultar extraño que adjuntáramos a la acepción «embarcación enemiga que se rinde o se toma por fuerza» (Salvá 1846) de presa tanto Mil. como Mar. (marina).

Además, exactamente en 56 ocasiones fue preciso recurrir al empleo de la marca diacrónica $^{26}$ ant. ([acepción] antigua o anticuada), lo que de nuevo conlleva la simultaneidad de dos marcas, eso sí, en este caso entre la temporal ant y alguna de las marcas diatécnicas ya especificadas, a excepción de lucha y luchar ${ }_{l}$, acepciones que, aunque portan la marca diacrónica mencionada, carecen en cambio de la de especialidad.

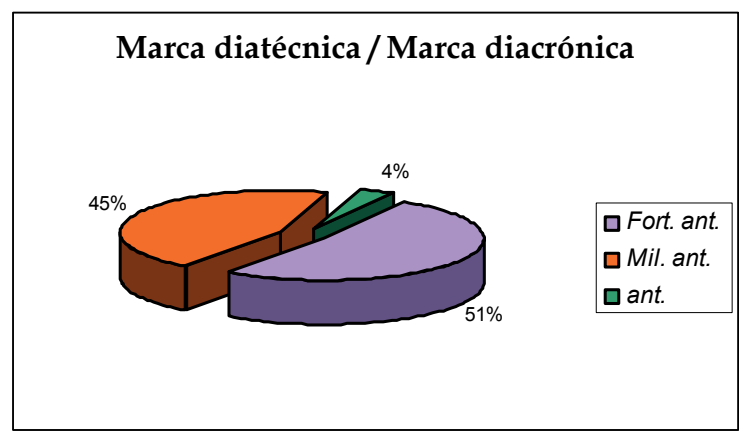

Figura 6: Gráfico sobre la combinación de marcas temáticas con la temporal ant.

Tras la realización de la presente investigación nos atrevemos a afirmar que, gracias a su léxico, el mundo militar antiguo está muy presente en la tratadística militar renacentista. A este respecto, consideramos a la siguiente cita sumamente clarificadora:

Conviene recordar que, contra lo que comúnmente tiende a pensarse, la desapari-
ción de un referente no tiene por qué acarrear la del signo que a él se refiere, pues
la lengua sirve permanentemente, entre otras cosas, para evocar un pasado ya ido.
Ni la palabra maravedi ni, menos aún, la palabra peseta son arcaísmos léxicos, por
más que hayan desaparecido ambas monedas (Álvarez de Miranda 2008: 31).

Esto es, como demuestra el hecho de que las voces que sirven para designarlas son recurrentes en el corpus manejado, debe notarse que las acepciones que en nuestro glosario van acompañadas de la marca ant. no son arcaísmos lingüísticos, sino que simplemente dan cuenta de realidades militares ya superadas en el Renacimiento. Por ejemplo, resulta especialmente significativa la frecuencia con la que los tratadistas aluden a las máquinas militares de otras épocas, con la intención de que con la comparación queden recalcados los beneficios de las modernas armas de fuego. Ahora bien,

26 «Entre [las marcas diasistemáticas] cabe citar las, a nuestro juicio, mal denominadas marcas diacrónicas, que sería preferible llamar simplemente temporales, puesto que su misión no es tanto asignar la palabra a una variedad diacrónica como indicar su grado de uso en el momento actual en relación o no con su antigüedad» (Porto Dapena 2002: 257). 
en nuestro caso, para dejar constancia de que no son términos propios de la fortificación abaluartada, consideramos adecuado emplear en ellos la marca diacrónica ant.

Por último, además de lucha y luchar ${ }_{l}$, otras 144 acepciones carecen de marca diatécnica o temática. Si tenemos en cuenta que la lengua técnica implica lo marcado, resulta evidente que su ausencia tiene también su propio valor. Por lo que se refiere a nuestro glosario, si bien, como ocurre con el resto, esos 146 sentidos corresponden a la milicia, su particularidad reside en que han logrado sobrepasar el ámbito estrictamente especializado.

\subsubsection{Definición}

A pesar de que la definición es la cuestión lexicográfica que mayor interés ha despertado entre los estudiosos, aún hoy sigue siendo la principal dificultad dentro de la redacción lexicográfica (ápud Porto Dapena 2002: 266).

Por consiguiente, para la consecución de esta delicada y costosa labor del lexicógrafo, además de ser esta una de las directrices del Diccionario de la ciencia y de la técnica del Renacimiento, tratamos de adaptar, siempre y cuando fuera posible, las definiciones existentes en otros repertorios. De este modo, la mayor parte de las definiciones prestadas proceden del Diccionario de Autoridades (= Aut.), del Diccionario castellano con las voces de las ciencias y las artes de Terreros (= Terr.), del Diccionario de uso del español (=DUE) de María Moliner, del Diccionario Salamanca de la lengua española $(=D S A L)$, del Diccionario del español actual $(=D E A)$, así como de la última edición del repertorio académico. Ahora bien, también hallamos definiciones útiles en varios de los numerosos diccionarios recopilados en el Nuevo tesoro lexicográfico de la lengua española: entre otros, el Nuevo diccionario de la lengua castellana de Vicente Salvá, el Diccionario de la lengua española de José Alemany y Bolufer y el Diccionario general y técnico hispano-americano de Manuel Rodríguez Navas.

Lógicamente, aparte de estos diccionarios generales, también han resultado fundamentales los cuantiosos repertorios militares de los que dispone nuestra lexicografía ${ }^{27}$.

Ahora bien, como se deduce de las múltiples definiciones carentes del paréntesis indicador de la fuente lexicográfica empleada, no son pocas las ocasiones en las que nos vimos obligados a emprender la difícil tarea de redactar nuestra propia definición lexicográfica, obstáculo generado por la ausencia del término en cuestión en los diccionarios manejados, o por no resultar conveniente la definición hallada para nuestro caso.

Somos conscientes de que la mayoría de nuestras definiciones sobrepasa los límites impuestos por las estrictamente lexicográficas. Sin duda, el ejemplo más extremo de esta tendencia la constituye la explicación aportada en caballero $o_{2}$, al igual que en su sinónimo plataforma ${ }_{3}^{28}$. En casos como este preferimos, en aras de una mejor com-

\footnotetext{
${ }^{27}$ Consúltese Sánchez Orense (2012a: 132-165) para conocer el panorama de la lexicografía española relativa a la milicia.

${ }^{28}$ La definición exacta que aportamos para esta acepción es: «En una fortaleza, defensa muy alta que se construye para descubrir las partes de la campaña por las que el enemigo puede acercarse sin ser visto, o para ofenderle desde allí aunque aún se encuentre lejos; y, en el caso de haber cerca cualquier monte o elevación, para igualar o superar su altura» (Sánchez Orense 2012: s. v. caballero 2 y plataforma . $_{\text {). }}$
} 
prensión, anteponer la claridad a la concisión, pese a ser esta una de las principales reglas que rige la elaboración de definiciones puramente lingüísticas.

Si se tiene en cuenta que uno de los objetivos del presente glosario es la de servir de ayuda al lector contemporáneo en la interpretación y completo entendimiento de la tratadística militar renacentista, se entenderá fácilmente el porqué de esta decisión.

\subsubsection{Ilustraciones}

Tras la definición, en todas las acepciones en las que localizamos una valiosa imagen que, a nuestro juicio, facilita la comprensión del concepto en cuestión, insertamos S junto con el número, entre paréntesis, de la ilustración a la que remitimos. Para no sobrecargar en exceso los artículos lexicográficos, las 173 figuras de que consta nuestro glosario se encuentran agrupadas en el «Catálogo de ilustraciones comentadas», apéndice situado justo después del denominado «Índice de variantes gráficas». Creemos que en el caso de las lenguas especializadas el empleo de ilustraciones resulta obligado, ya que apuntalan la información lexicográfica proporcionada.

Eso sí, nos gustaría precisar que de todas las ramas militares contempladas la que ha generado el mayor número es, indudablemente, la fortificación, lo que no resulta extraño si tenemos en cuenta la complejidad de sus contenidos. Por ejemplo, tras definir las voces sinónimas fianco, espalda y través como la «parte del baluarte que une su frente con la cortina, o distancia comprendida entre el ángulo de la cortina y la cara o frente del baluarte» (Sánchez Orense 2012), fuimos conscientes de la necesidad de aportar una imagen ilustradora que fuese capaz de clarificar este concepto de fortificación tan complejo. Así, en el caso de través adjuntamos esta imagen,

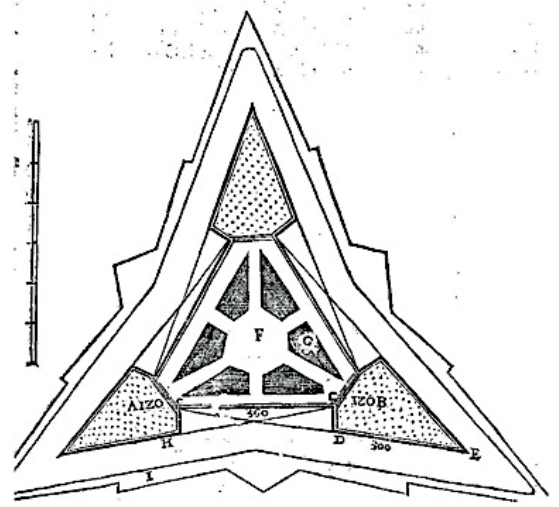

Figura 7: En Rojas (1598: fol. 40v)

a la que acompañamos de la siguiente observación: «En esta planta de una fortaleza en figura triangular, $\mathrm{CD}$ representa uno de los fiancos o traveses que hay». Esto es, CD es la parte del baluarte B que une su frente DE con la cortina CC. Además de este acopio de información, también para fianco decidimos incluir la siguiente figura, en la que matizamos que en este caso era $\mathrm{CD}$ quien representaba uno de los fiancos o traveses 
del baluarte B, ya que es el segmento que marca la distancia comprendida entre el ángulo de la cortina CC y la frente DE del baluarte B:

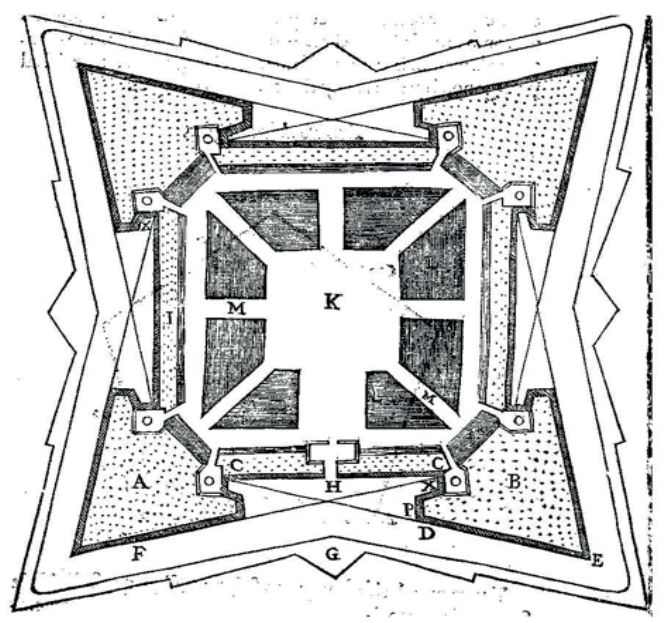

Figura 8: En Rojas (1598: fol. 42r)

Podemos afirmar que la incorporación de imágenes constituye una de las principales aportaciones de nuestro trabajo, ya que de los múltiples diccionarios militares de que goza nuestra lengua, los cuales son parte importante del corpus lexicográfico que manejamos, solo en dos, concretamente en el de Luis de Agar y en el de Mariano Rubió y Bellvé, se constata una preocupación por aportar figuras que autoricen las definiciones.

\subsubsection{Ejemplos}

Además, para cada acepción ofrecemos de uno a tres ejemplos ilustrativos, extraídos, lógicamente, del corpus del DICTER. Es al final del glosario, en «Corpus del Diccionario de la ciencia y de la técnica del Renacimiento español», donde aportamos todos los datos bibliográficos pertinentes, mientras que en «Listado abreviado de autores» anotamos la forma exacta en que citamos esas obras del corpus.

Con respecto a su extensión, coincidimos con Pascual y García (2007: 206) en señalar que sean tan largos como «exija la correcta interpretación de la palabra».

Debemos precisar que, en la selección de estos pasajes, que sirven para avalar la definición, nos basamos en la claridad del contexto para la determinación del contenido semántico del vocablo en cuestión.

En principio partimos de la idea de aprovechar el ejemplo más antiguo de cada acepción detectada. Sin embargo, como también atendimos al principio de transparencia y sentido completo, en el caso de no cumplirlo desechamos esa temprana ocurrencia (cf. asedio $_{1}$, riza, sitiar y trinchera entre otros). 


\subsubsection{Relaciones semánticas}

Después de los ejemplos, pese a ser conscientes de las dificultades que conlleva esta tarea, colocamos la información relativa a las relaciones semánticas que contraen entre sí las unidades léxicas de nuestro glosario. Así pues, indicamos todos los casos de antonimia y sinonimia detectados, precedidos por ANT. y SIN. respectivamente.

Podemos afirmar que el léxico militar del período estudiado se caracteriza por una fuerte presencia de voces sinónimas, lo que implica que la información acerca de este fenómeno semántico sea una de las principales características del presente repertorio.

Téngase en cuenta, además, que, de acuerdo con una de las reglas establecidas para el Diccionario de la ciencia y de la técnica del Renacimiento, los términos semánticamente equivalentes de nuestro glosario poseen exactamente la misma definición, eficaz sistema con el que conseguimos evitar los obvios inconvenientes que conlleva el uso desmedido de las remisiones o definiciones sinonímicas.

\subsubsection{Información enciclopédica}

En numerosas ocasiones proporcionamos información adicional con el fin, entre otros, de facilitar la total comprensión del significado exacto de los conceptos militares atendidos. Así pues, estas peculiares explicaciones, que van siempre precedidas de ENCICL., pueden referirse tanto al lema de cabecera, como a alguna de sus acepciones e incluso a las distintas unidades pluriverbales recogidas.

En definitiva, se trata de un apartado que permite ampliar aquellos casos en los que juzgamos que la combinación de la definición con los ejemplos no resulta suficientemente clarificadora, o para ofrecer una mayor precisión, sobre todo en los conceptos más problemáticos.

Bajo esta denominación se agrupan, por lo tanto, distintos tipos de información: otros ejemplos ilustrativos del corpus, aclaraciones y explicaciones extraídas de las más variadas obras, otras definiciones, etc.

Si se tiene en consideración que en la realización de esta investigación nos propusimos ser totalmente exhaustivos a la hora de dar cuenta de los conceptos técnicos de la milicia renacentista, lo que, a nuestro juicio, contribuirá a salvar las múltiples lagunas terminológicas existentes, se comprenderá fácilmente la trascendencia que le otorgamos a este apartado. A esta consideración responden los numerosos casos en los que la información enciclopédica aportada destaca por su llamativa extensión.

\subsubsection{Acepciones y unidades pluriverbales}

Como no podía ser de otra manera, el Glosario de fortificación y arte militar renacentistas, aparte de las entradas, consta de otras acepciones, así como de unidades pluriverbales. En concreto, hasta 290 acepciones se encuentran en el interior de algún artículo lexicográfico, mientras que 131 es el total de unidades pluriverbales registradas.

Muchos artículos lexicográficos están compuestos por más de una acepción. Estas acepciones van enumeradas y funcionan autónomamente, de manera que, además 
de su definición, pueden estar categorizadas, tener sus propias marcas de uso, sus ejemplos, sus sinónimos y antónimos, etc. (Garriga 2003: 107).

Debe notarse que las acepciones se han dispuesto en párrafos distintos, separadas por dos saltos adicionales de línea, y aparecen numeradas correlativamente, con excepción de la primera.

Con respecto al orden de las acepciones, acordamos finalmente situar en primer lugar la acepción más general o difundida dentro del área de especialidad o, incluso, dentro de la lengua estándar, y seguir por las más particulares hasta llegar a las unidades pluriverbales.

Advertimos, para facilitar su localización, que en la colocación de las formas complejas nos remitimos a lo estipulado por el DRAE (2001), a saber, que se encuentran ubicadas bajo «el artículo correspondiente al elemento sustantivo», motivo por el que media luna, por ejemplo, no se define bajo media, o la forma canónica medio, sino bajo luna:

luna, luna [del lat. lüna 'íd.'. Orígenes del idioma $(D C E C H)]$.

media [Mendoça, Theórica y práctica, 1596]. cmpt. sintag. Fort. Obra de fortificación que se construye delante de los baluartes, la cual consta de dos caras que forman un ángulo saliente y de una gola o parte trasera curvada hacia el interior. (fig. 104)

Mendoça, Theórica y práctica, 1596, pág. 142: Y a la fin se ha de [...] procurar mantener siempre la muralla (sin dar lugar al miedo, que es poderoso señor, siempre que se le abre la puerta) para formar detrás d'ella nuevos fossos, reparos o medias lunas, que raras vezes defendieron tierra, perdiéndose la muralla d'ella.

Ahora bien, como puede constatarse, en este caso solo recogemos el sentido especializado designado por la forma compuesta, al no resultar pertinentes, desde el punto de vista terminológico, los sentidos de la voz que la encabeza. No obstante, consideramos necesario ofrecer la procedencia etimológica de la lexía simple de referencia. Esto sucede, aparte de con media luna, con arquitectura militar, arte militar, a la deshilada, hecho de armas, de suelo y de(l) terreno, entre otras unidades pluriverbales.

\section{CONSIDERACIONES FINALES}

Con este Glosario de fortificación y arte militar renacentistas nos proponemos llenar uno de los múltiples vacíos en la lexicografía histórica del español, ya que aunque esta disciplina cuenta con un numeroso elenco de diccionarios militares, la mayoría apenas son conocidos, lo que hace muy difícil su aprovechamiento.

Además, aspiramos a que nuestro repertorio sea capaz de paliar la carencia de inventarios léxicos de la milicia asentados sobre sólidos principios lingüísticos, pues la mayoría de los existentes han sido confeccionados con criterios ajenos a la filología. 
En definitiva, la presente investigación pretende ser una aportación útil para los estudios de lexicología y lexicografía históricas del español, si bien no descartamos su interés en lo que respecta a los de historia de la ciencia.

\section{REFERENCIAS BIBLIOGRÁFICAS}

Fuentes primarias

Álaba Y ViAmont, Diego de (1590): El perfeto capitán instruido en la diciplina militar y nueva ciencia de la Artillería, Madrid, Pedro Madrigal.

Alberto, León Baptista (1582): Los diez libros de Architectura, Madrid, Alonso Gómez, trad. Francisco Loçano.

Collado De LeBriXA, Luys (1592): Plática manual de Artillería, Milán, Pablo Gotardo Poncio.

FERNÁNDEZ DE ENCISO, Martín (1530²): Suma de Geographía, Sevilla, Juan Cromberger.

FERROFINO, Julián (mss. 1599): Descrizión y tratado muy breve y lo más probechoso de Artillería.

García de PALACIO, Diego (1583): Diálogos militares, México, Pedro Ocharte.

GonzÁlez de MedinA, Diego (1599): Examen de fortificación, Madrid, Pedro Várez de Castro.

Lechuga, Cristóval (1611): Discurso del Capitán Cristóval Lechuga, en que trata de la Artillería y de todo lo necessario a ella, Milán, Marco Tulio Malatesta.

MENDOÇA, Bernardino de $\left(1596^{2}\right)$ : Theórica y práctica de guerra, Anveres, Imprenta Plantiniana.

MONTES, Diego (1537): Instrucción y regimiento de guerra, Zaragoza, George Coci.

Mosquera DE FIGUeROA, Christóval (1596): Comentario en breve compendio de disciplina militar, Madrid, Luis Sánchez.

RoJAs, Christóval de (1598): Teórica y práctica de fortificación, Madrid, Luis Sánchez.

- (1613): Compendio y breve resolución de fortificación, Madrid, Juan de Herrera.

- (mss. 1607): Sumario de la milicia antigua y moderna.

UfAno, Diego (1613): Tratado de la Artillería, Brusselas, Juan Momarte.

Vitruvio Pollión, Marco (1582): De Architectura, Alcalá de Henares, Juan Gracián, trad. Miguel de Urrea.

Repertorios lexicográficos

AGAR, Luis de (1853-1866): Diccionario ilustrado de los pertrechos de guerra y demás efectos pertenecientes al material de artillería, Madrid, Lit. Tormentaria de C. Echauri.

Alemany y Bolufer, José (1917): Diccionario de la lengua española, Barcelona, Ramón Sopena.

AlmiranTe, José (2002 [1869]): Diccionario militar, Madrid, Ministerio de Defensa.

BATTAGLiA, Salvatore (1961-2002): Grande dizionario della lingua italiana, Torino, Unione Tipografico-Editrice Torinese.

BAtTisti, Carlo y Giovanni Alessio (1975): Dizionario etimologico italiano, Firenze, G. Barbèra Editore, Università degli Studi. 
Beltrami, Pietro, dir. (en red): Tesoro della lingua italiana delle origini, Firenze, Istituto Opera del Vocabolario Italiano. (TLIO). <http://tlio.ovi.cnr.it/TLIO>

Corominas, Joan y José Antonio Pascual (1980-1991): Diccionario crítico etimológico castellano e hispánico, Madrid, Gredos. (DCECH).

FERNÁNDEZ MANCHEÑO, José (1822): Diccionario militar portátil, o recopilación alfabética de todos los términos propios de las ciencias militares, explicación de los empleos de la milicia y sus obligaciones [...], Madrid, Imprenta de Miguel de Burgos.

GAFFIOT, Félix (2000 [1934]): Le Grand Gaffiot: dictionnaire latin-français, París, Hachette.

GutiÉRrez CuAdrado, Juan, dir. (1996): Diccionario Salamanca de la lengua española, Madrid, Santillana, Ediciones Universidad de Salamanca. (DSAL).

IMBS, Paul, dir. (1971-1986): Trésor de la langue française. Dictionnaire de la langue du XIXe et $d u$ XXe siècle, París, Centre National de la Reserche Scientifique-Gallimard. (TLF).

LORENZO CELORRIO, Ángel (1996): Compendio de vocablos referidos a los castillos, Madrid, Ediciones Lancia.

Mancho Duque, María Jesús, dir. (en red): Diccionario de la ciencia y de la técnica del Renacimiento español, Salamanca, Ediciones Universidad de Salamanca. (DICTER). $<\mathrm{http}: / /$ dicter.eusal.es/>

Miguel, Raimundo de (2003): Nuevo diccionario latino-español etimológico, Madrid, Visor Libros.

Moliner, María (1998²): Diccionario de uso del español, Madrid, Gredos. (DUE).

PHARIES, David (2002): Diccionario etimológico de los sufijos españoles, Madrid, Gredos.

Real ACAdemia Española (1990 [1726-39]): Diccionario de Autoridades, Madrid, Gredos. (Aut.).

- (1817 $)$ : Diccionario de la lengua castellana, Madrid, Imprenta Real. (DRAE).

(2001 $\left.{ }^{22}\right)$ : Diccionario de la lengua española, Madrid, Espasa Calpe. (DRAE).

(2001): Nuevo tesoro lexicográfico de la lengua española, Madrid, Espasa Calpe. (NTLLE).

RodRÍGUEZ NAVAS Y CARRASCO, Manuel (1918): Diccionario general y técnico hispanoamericano, Madrid, Cultura Hispanoamericana.

RuBió Y Bellvé, Mariano (1895-1901): Diccionario de ciencias militares, Barcelona, Administración de la Revista científico-militar y Biblioteca militar.

SALVÁ, Vicente (1846): Nuevo diccionario de la lengua castellana, que comprende la última edición íntegra, muy rectificada y mejorada del publicado por la Academia Española [...], París, Vicente Salvá.

SÁNCHEZ ORENSE, Marta (2012): «Glosario de fortificación y arte militar renacentistas», en La fortificación y el arte militar en los tratados renacentistas en lengua castellana: estudio lexicológico y lexicográfico, Salamanca, Universidad de Salamanca, pp. 199-733.

SeCO, Manuel, Olimpia de ANDRÉs y Gabino RAMOs (1999): Diccionario del español actual, Madrid, Santillana. (DEA).

SEgura Munguía, Santiago (2001): Nuevo diccionario etimológico latín-español y de las voces derivadas, Bilbao, Universidad de Deusto.

- (2007): Diccionario por raices del latín y de las voces derivadas, Bilbao, Universidad de Deusto.

TERREROS Y PANDO, Esteban de (1987 [1786-1793]): Diccionario castellano con las voces de las ciencias y las artes, Madrid, Arco/Libros. (Terr.). 
Estudios lingüísticos e históricos

Álvarez De Miranda, Pedro (2008): «Las discontinuidades en la historia del léxico», en Company Company y Moreno de Alba, eds., Actas del VII Congreso Internacional de Historia de la Lengua Española, Madrid, Arco/Libros, vol. 1, pp. 1-44.

ARNTZ, Reiner y Heribert PICHT (1995): Introducción a la terminología, Madrid, Fundación Germán Sánchez Ruipérez, Pirámide.

Blas Nistal, Cristina (2007): Estudio léxico de los tratados de artillería españoles del siglo XVI, Tesis Doctoral inédita, Universidad de Salamanca.

CAMPILlO, Antonio $\left(2008^{2}\right)$ : La fuerza de la razón. Guerra, estado y ciencia en el Renacimiento, Murcia, Universidad de Murcia.

COLÓN DOMÉNECH, Germán (2008): «Joan Coromines i les llengües romàniques» en T. Cabré, M. Prat y J. Torruella, eds., Joan Coromines i la filologia romànica, Bellaterra, Universitat Autònoma de Barcelona, pp. 115-122.

DÍAZ CAPMANY, Carlos (2004): La fortificación abaluartada. Una arquitectura militar y política, Madrid, Ministerio de Defensa.

FAJARDO AGUIRRE, Alejandro (1996-1997): «Las marcas lexicográficas: conceptos y aplicación práctica en la Lexicografía española», Revista de Lexicografía, III, pp. 31-57.

GARRIGA ESCRIBANO, Cecilio (2003): «La microestructura del diccionario: las informaciones lexicográficas», en A. M. Medina Guerra, coord., Lexicografía española, Barcelona, Ariel, pp. 103-126.

JiMÉNEZ RÍos, Enrique (2001): Variación léxica y diccionario: Los arcaísmos en el diccionario de la Academia, Madrid, Iberoamericana-Vervuert.

MANCho DuQue, María Jesús (2003): «Aproximación al léxico de la ciencia aplicada en el Renacimiento hispano», Asclepio, LV, 2, pp. 27-42.

- (dir.) y Mariano QUIRÓS GARCÍA, coord. (2005): La ciencia y la técnica en la época de Cervantes: textos e imágenes, Salamanca, Universidad de Salamanca.

OtaOla Olano, Concepción (2004): Lexicología y semántica léxica. Teoría y aplicación a la lengua española, Madrid, Ediciones Académicas.

PAscual Rodríguez, José Antonio y Rafael García PÉREZ (2007): Límites y horizontes en un diccionario histórico, Salamanca, Diputación de Salamanca.

Porto DAPEnA, José-Álvaro (2002): Manual de técnica lexicográfica, Madrid, Arco/Libros.

SÁNCHEZ ORENSE, Marta (2012a): La fortificación y el arte militar en los tratados renacentistas en lengua castellana: estudio lexicológico y lexicográfico, Salamanca, Universidad de Salamanca.

(2012b): «Aproximación al léxico de la poliorcética renacentista: Cuestiones lexicográficas», en A. Nomdedeu, E. Forgas y M. Bargalló, eds., Avances de lexicografía hispánica, Tarragona, Universitat Rovira i Virgili, pp. 469-481. 